\title{
Accounts
}

\section{Photophysical Properties and Photosubstitution and Photoredox Reactions of Aromatic Nitro Compounds \#}

\author{
Ryoichi Nakagaki* and Kiyoshi Mutai*,† \\ Faculty of Pharmaceutical Sciences, Kanazawa University, Takaramachi, Kanazawa, Ishikawa 920 \\ $\nmid$ Department of Chemistry, Graduate School of Arts and Sciences, The University of Tokyo, Komaba, Meguro, Tokyo 153
}

(Received September 1, 1995)

\begin{abstract}
Orientation rules for photochemical nucleophilic substitutions are deduced from intramolecular photoreactions of some bichromophoric chain molecules, $p-\mathrm{O}_{2} \mathrm{NC}_{6} \mathrm{H}_{4} \mathrm{O}\left(\mathrm{CH}_{2}\right)_{n} \mathrm{NHC}_{6} \mathrm{H}_{5}$. The lower homologues undergo photochemical nucleophilic substitutions which can be classified as a Smiles-type photorearrangement. The photochemistry of this type of bifunctional chain species depends upon the methylene chain length. When the chain length is sufficiently long, the photorearrangement is totally forbidden. Photoredox reactions are the only accessible reaction processes for the higher homologues. The photoredox reaction consisting of cage and escape pathways is modulated by an external magnetic field. The magnetic field effects on the end product distribution are due to changes in the intersystem crossing rate induced by hyperfine interaction within biradical intermediates.
\end{abstract}

The inter- and intramolecular photoredox reactions have been investigated for nitrobenzene derivatives since the beginning of this century. Photochemical reduction of benzophenone was correctly interpreted in 1900 by Ciamician and Silber. ${ }^{1)}$ They established the structure of the photoproduct obtained on photolysis of benzophenone in ethanol as benzpinacol instead of a condensation product of benzophenone with acetaldehyde. These authors briefly reported photoreduction of nitrobenzene in the same paper. They discovered an intramolecular photoredox reaction of $o$-nitrobenzaldehyde. ${ }^{2)} o$-Nitrobenzaldehyde was converted to $o$ nitrosobenzoic acid when exposed to sunlight (Scheme 1). This type of intramolecular photochemistry involving neighboring group oxidation have attracted the attention of photochemists ever since. ${ }^{3)} o$-Substituted nitrobenzenes constitute a wide variety of compounds which are of some interest in the development of photochromic substances, ${ }^{4)}$ photoremovable protective groups, ${ }^{5-8)}$ photoactivable probes, ${ }^{9-11)}$ and photoresists. ${ }^{12-15)}$ In contrast to this, a long-range intramolecular oxidation with photoexcited nitrobenzene chromophore

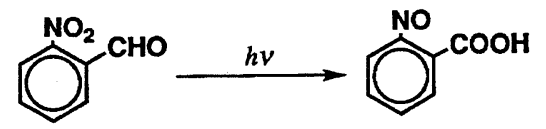

Scheme 1.

\#This paper is dedicated to Professor Saburo Nagakura on the occasion of his 75 th birthday. has not been developed until recently ${ }^{16,17)}$ (Scheme 2). This kind of photochemistry can be regarded as a modification of remote oxidation with benzophenone derivatives. ${ }^{18)}$ Such photoredox reactions were elucidated as a synthetic method for site-selective oxidation of steroids. Mechanistic studies on photochemical remote oxidations have been reported for $N$-alkylaniline derivatives. ${ }^{19)}$

The second type of photochemical reaction of nitroaromatic species is nucleophilic photosubstitution reaction, which has been studied by a research group at Leiden since $1956 .{ }^{20)}$ A feature of nucleophilic photosubstitutions is metaactivation with respect to a nitro group. ${ }^{21)}$ A typical example is shown in Scheme 3. In 1976, Havinga and Cornelisse noted that the number of reactions and the variations of the phenomena observed have gradually made the field look chaotic. ${ }^{21,22)}$ In 1982, one of us has proposed a new interpretation for an anomalous para-orientation in nucleophilic photosubstitution. ${ }^{23}$ This approach has been applied to some nitro-aromatic species ${ }^{24-26)}$ and is accepted by other researchers. ${ }^{27-31)}$ The photochemical Smiles rearrangement,

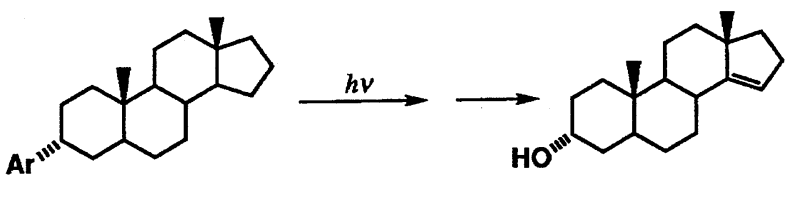

$\mathrm{Ar}=\mathrm{OCOCH}_{2} \mathrm{CH}_{2} \mathrm{C}_{6} \mathrm{H}_{4} \mathrm{NO}_{2}-p$

Scheme 2 . 


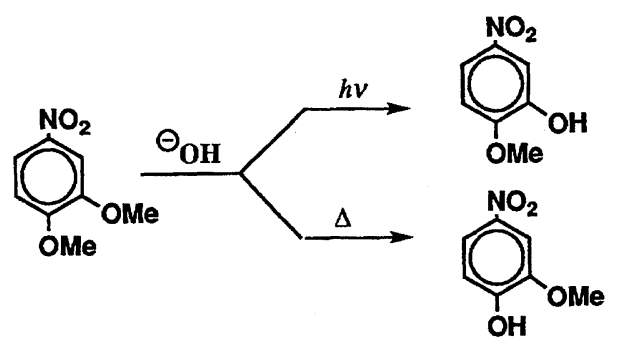

Scheme 3.

an intramolecular nucleophilic photosubstitution, was first reported for 2-aminophenoxy-s-triazine derivatives. ${ }^{32)}$ Other types of photorearrangements have been examined for methylene-linked chain molecules containing nitro-aromatic chromophore and nucleophilic moiety. ${ }^{33-37)}$

In comparison with photophysical and photochemical properties of benzophenone and related compounds, those of nitrobenzene derivatives have not been fully understood until recently. This is partly due to the complexity of lowlying excited states of nitro-aromatic species and to secondary processes of primary photoproducts. The nature of low-lying excited states involved in nitro-aromatic photochemistry is characterized as $n, \pi^{*}, \pi, \pi^{*}$, or intramolecular charge-transfer state, while the intramolecular charge-transfer state is of minor importance for the aromatic carbonyl compounds. The photochemical secondary processes are dependent on the nature of chromophores in the end products. As far as the photoredox reactions are concerned, the primary product from nitrobenzene is nitrosobenzene, whose reactivity toward radical species is higher than that of the parent compound. Therefore the photoredox reactions of nitrobenzene involving radical species may become complicated on prolonged photolysis. Furthermore, since nitroso-aromatic species generally exhibit a red-shifted band with intensity comparable to that of the corresponding nitro compounds, the selective photoreduction of the parent nitro compound is not completely achieved. On the other hand, photoreduction of aromatic carbonyl species results in contraction of $\pi$-electron conjugated systems. For example, the photoreduction product of benzophenone is a simple dimer of ketyl radicals.

The purpose of this account is three-fold:

(1) to present orientation rules for photochemical nucleophilic substitution reactions;

(2) to show that some bifunctional chain species containing the nitro-aromatic chromophore and anilino group undergo two distinctly different photochemical reaction pathways, depending upon the chain length linking the two functional groups;

(3) to describe magnetic field effects on the product yields for photoredox reactions of nitro-aromatic species which involve biradical intermediates.

Since the intermolecular photoredox and photosubstitution reactions of nitro-aromatic compounds have been well documented, ${ }^{31,38-49)}$ the present review puts a special emphasis on the intramolecular photochemistry of nitro-aromatic species. We have been investigating intramolecular photochemistry for a series of methylene-linked chain molecules containing a nitro-aromatic chromophore and reductant or nucleophilic moieties.

The intramolecular photochemistry of chain molecules has some advantages. The formation yield for reaction intermediates and end products may be high, because intramolecular photochemical reactions generally occur more efficiently than the corresponding intermolecular analogues. When the excited state is short-lived, an intermolecular reaction may be inefficient, because reactive collisions cannot occur during the lifetime of the excited species. The role of the methylene chain is to prevent diffusion of the reactant and reagent. The intramolecular reaction takes place at such low concentration that the intermolecular reaction rarely occurs. Secondary processes involving the reactant and the primary photoproduct can be suppressed by employing a sufficiently low concentration.

\section{Spectroscopic Properties of Nitro-Aromatic Species}

Electronic absorption and emission properties of nitroaromatic compounds will be briefly described here. The discussion in this section is limited to a review of spectroscopic data most appropriate to explain the photochemistry.

Absorption Spectroscopy of Nitrobenzenes. The nature of the longest wavelength absorption band of nitrobenzene was not established until 1975. It was assigned as $n, \pi^{*}$ or $\pi, \pi^{*}$ transition. ${ }^{38,50)}$ The $n, \pi^{*}$ transition was thought to be submerged under the high-intensity $\pi, \pi^{*}$ band. ${ }^{51)}$ This idea was verified by Vidal and Murrell in $1975 .{ }^{52)}$ A puzzling feature of the electronic spectrum of nitrobenzene has been the red-shift of the longest wavelength absorption band (2500$3300 \mathrm{~cm}^{-1}$ ) on changing from nonpolar to polar solvents. ${ }^{52)}$ The assignment of the band to an $n, \pi^{*}$ transition is contrary to the characteristic blue-shift of the $n, \pi^{*}$ bands. The anomalous solvent effects have been revealed by absorption spectroscopy in the gaseous state and the solution phase. ${ }^{52)}$ The apparent red-shift is due to the underlying intensity from the $\pi, \pi^{*}$ band whose first maximum is at $34750 \mathrm{~cm}^{-1}$ in the gas phase. This allowed band shifts to the lower energy side in polar solvents. In methanol the $n, \pi^{*}$ band in almost buried under the $\pi, \pi^{*}$ band. The $T_{1}$ state of nitrobenzene has been assigned as $n, \pi^{*}$ type from photochemical studies in 2 propanol. ${ }^{53)}$ Carsey, Findley, and McGlynn have suggested that the $T_{1}$ state of nitrobenzene is of $\pi, \pi^{*}$ type. ${ }^{54}$

At least three different low-lying excited states are involved in the longest wavelength absorption band for $p$ $\mathrm{X}-\mathrm{C}_{6} \mathrm{H}_{4} \mathrm{NO}_{2}$ molecules. These are $\mathrm{L}_{\mathrm{a}}$ (long-axis polarization), $\mathrm{L}_{\mathrm{b}}$ (short-axis polarization), and $n, \pi^{*}$ states. ${ }^{55-60)}$ The important role of intramolecular charge-transfer interaction has been pointed out by Nagakura and co-workers. ${ }^{50,56-58)}$ In the case of substituted nitrobenzenes $\mathrm{X}-\mathrm{C}_{6} \mathrm{H}_{4} \mathrm{NO}_{2}$, the relative location of these three states depends upon the position of substituent $X$, the electron-donating ability of $X$, and solvent polarity. ${ }^{55-60)}$ It may be rather difficult to identify precisely $n, \pi^{*}$ states of highly polar nitrobenzene derivatives. Anomalous absorption spectral behavior has been observed for $p$-nitroaniline in 1,1,1,3,3,3-hexafluoro-2-propanol. This anomaly is due to strong hydrogen bonding interaction be- 
tween the solute and the solvent. ${ }^{61)}$

Emission Spectroscopy of Nitrobenzenes. The luminescence of nitrobenzene consists entirely of phosphorescence (emission maximum at $21100 \mathrm{~cm}^{-1}$, phosphorescence lifetime $0.1-1 \mathrm{~s}){ }^{62)}$ Repeated experiments with vacuum-distilled and zone-refined nitrobenzene have shown that the nitrobenzene triplet does not give long-lived emission and that the phosphorescence quantum yield is $\leq 10^{-3} \cdot{ }^{63)}$ The emission, therefore, is probably spurious. If it be intrinsic to nitrobenzene, it is probable that this phosphorescence is not due to the $n, \pi^{*}$ transition of nitrobenzene in view of the large S-T separation (ca. $4000 \mathrm{~cm}^{-1}$ ).

When the second substituent is introduced into the benzene ring of nitrobenzene, the nature of the lowest excited states is modified depending upon the electron-donating ability of the substituent. When some electron-accepting substituents (e.g. nitro and cyano) are bonded at the para-position, the lowest $\pi, \pi^{*}$ transition energy slightly decreases. Consequently, the $n, \pi^{*}$ state may either undergo a slight spectral shift or remain almost the same as the mono-nitro species. On the other hand, when the electron-donating ability is increased the $\pi, \pi^{*}$ absorption band undergoes an appreciable red-shift. ${ }^{5-60)}$ The lowest excited singlet and triplet states are both of $\pi, \pi^{*}$ type. Table 1 lists the phosphorescence lifetime and the nature of $\mathrm{T}_{1}$ state.

The lowest excited triplet state of $\mathrm{X}-\mathrm{C}_{6} \mathrm{H}_{4} \mathrm{NO}_{2}$ species is of $\pi, \pi^{*}$ character, when the electron-donating substituent $\mathrm{X}$ is at least as strong as hydroxy group. ${ }^{54)}$ When the strongly electron-donating group is attached, the lowest excited state becomes intramolecular charge-transfer state. ${ }^{64)} \mathrm{We}$ are now in a position to explain the nature of the excited triplet states. It is evident from the data that the phosphorescence lifetime reported for nitro-aromatics is larger than a few milliseconds, which is a commonly observed characteristic of $\pi, \pi^{*}$ triplets (Table 1).

The relationship between the spectroscopic and photochemical properties of nitrobenzene derivatives can be interpreted in terms of nature of the lowest excited triplet state. Three types of excited state are characterized as $n, \pi^{*}, \pi, \pi^{*}$, and intramolecular charge-transfer states. The $n, \pi^{*}$ state is intimately related with photoinduced hydrogen abstraction,

Table 1. Phosphorescence Lifetimes of Substituted Benzene

\begin{tabular}{ccccc}
\hline Molecule & $\mathrm{T}_{1}$ type & Solvent & $\tau_{\mathrm{p}} / \mathrm{ms}^{\mathrm{a}}{ }^{\mathrm{r}}$ & Ref. \\
\hline Benzene & $\pi, \pi^{*}$ & $\mathrm{EPA}^{\mathrm{b})}$ & 6300 & 65 \\
Benzaldehyde & $\mathrm{n}, \pi^{*}$ & $\mathrm{EG}^{\mathrm{c})}$ & 6.6 & 66 \\
$p$-Nitrophenol & $\pi, \pi^{*}$ & $\mathrm{MCH}^{\mathrm{d})}$ & 150 & 67 \\
$p$-Nitrophenol & $\pi, \pi^{*}$ & $\mathrm{EtOH}$ & 260 & 67 \\
$p$-Nitroanisole & $\pi, \pi^{*}$ & $\mathrm{MCH}$ & 110 & 67 \\
$p$-Nitroaniline & $\pi, \pi^{*}$ & $\mathrm{EtOH}$ & 400 & 67 \\
$p$-DMNA & $\pi, \pi^{*}$ & $\mathrm{MCH}$ & 210 & 67 \\
$p$-DMNA & $\pi, \pi^{*}$ & $\mathrm{EtOH}$ & 420 & 67 \\
\hline
\end{tabular}

a) $\tau_{\mathrm{p}}$, phosphorescence lifetime at $77 \mathrm{~K}$. b) EPA, mixed solvent of ether-isopentane-ethanol with volume ratio of $5: 5: 2$. c) $\mathrm{MCH}$, methylcyclohexane. d) EG, ethylene glycol. e) $p$ DMNA, $N, N$-dimethyl-p-nitroaniline.

and the $\pi, \pi^{*}$ state with nucleophilic photosubstitution. The intramolecular charge-transfer state is least reactive among the three states (vide infra).

Inter- and Intramolecular Photochemical Nucleophilic Substitution Reactions

Orientation Rules. As already pointed out, one of the essential features of nucleophilic photosubstitution is the meta activation with respect to the nitro group (Scheme 3). Rationalization of the meta-orienting selectivity have been reported on the basis of frontier molecular orbital theory. ${ }^{68)}$ Ordinary meta-activation is explained by Rule $1 .^{25)}$

Rule 1: Photosubstitutions with regioselectivity controlled by electron density in HOMO involve a one-step formation of a $\sigma$-complex through direct interaction between an excited aromatic substrate and a nucleophilic reagent (Scheme 4).

The intramolecular nucleophilic type photosubstitution (photo-Smiles rearrangement) provides suitable examples for mechanistic and orientation studies. Ordinary meta-activation has been observed for the photorearrangement of aliphatic amino derivatives reported by Wubbels and coworkers, ${ }^{36,37)}$ whereas we have identified para-orientation for a series of $m$ - and $p$-nitrophenoxyl derivatives containing anilino moiety. ${ }^{33-35,69,70)}$ Completely different orientations have been observed for two $m$-nitrophenoxyl derivatives (Scheme 5). This anomalous para regioselectivity is explained by Rule $2 .^{25)}$

Rule 2: Photosubstitutions with LUMO-controlled regioselectivity involve an electron-transfer from a nucleophile to a nitro-aromatic substrate in the excited state and subsequent

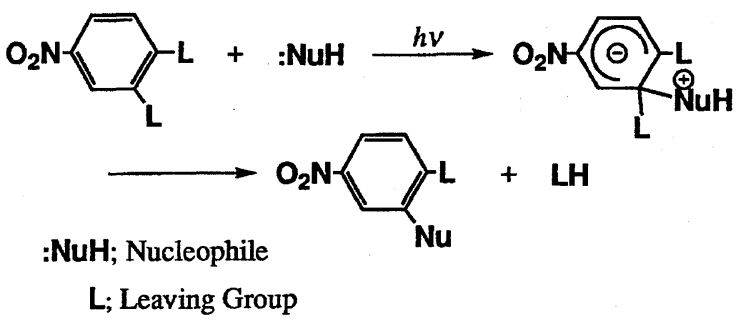

Scheme 4.
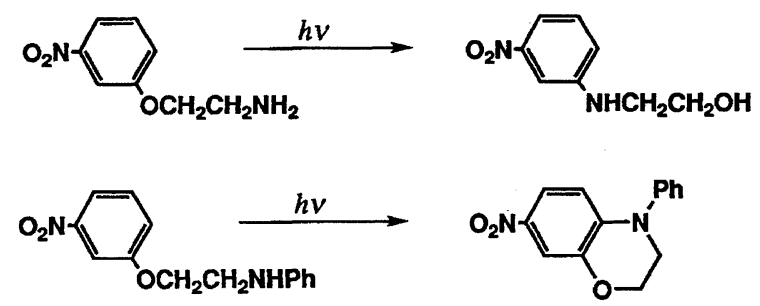

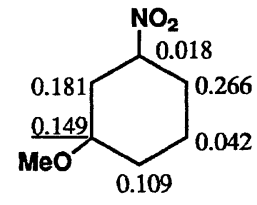

HOMO

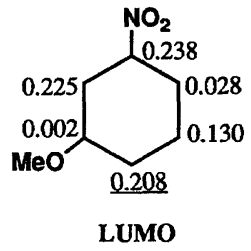

Scheme 5. Photoreactions and frontier electron density maps (CNDO/2) of $m$-nitrophenoxy ethers. $\left.{ }^{25}\right)$ 
recombination of the resultant radical ion pair (Scheme 6).

This orientation Rule 2 is based on the observation that irradiation of the compound of type 1 induced intramolecular electron transfer from anilino to nitrophenoxy groups, yielding a radical ion pair 2 (Scheme 7). Generation of these radical ions has been confirmed by means of laser flash photolysis. ${ }^{34,70-72)}$

These rules indicate that the discrimination of the orientation of a photosubstitution reaction depends on the ionization potential of a nuleophile so far as the same substrate is adopted. Thus the compound with $\mathrm{N}$-alkylanilino group of lower ionization potential ( $N$-methylaniline 7.65 $\mathrm{eV})^{73)}$ shows para-substitution (LUMO-controlled), whereas that with aliphatic amino group of higher potential (ethylamine $9.64 \mathrm{eV})^{74)}$ gives meta-substituted product (HOMOcontrolled) (Scheme 5). meta-Substitution observed in the photohydrolysis of 1,2-dimethoxy-4-nitrobenzene with hydroxide anion is therefore explained by Rule 1 or HOMOcontrolled regioselectivity, while the corresponding photorearrangement involving anilino group should exhibit pararegioselectivity as expected from the frontier electron density (FED) of LUMO (Scheme 8). ${ }^{25}$ Of course, Rule 2 is not limited to intramolecular reactions. Irradiation of each of three isomers of chloronitrobenzenes in liquid ammonia gives a mixture of nitroanilines and chlronitroanilines. ${ }^{75)}$ The structure of the products can be explained by Rule 2; for instance, upon irradiation of $p$-chloronitrobenzene at $-60{ }^{\circ} \mathrm{C}$ gives a mixture of $p$-nitroaniline (45\%) and 5-chloro-2-nitroaniline $(10 \%)$. The substitution takes place at ortho and para positions with regard to nitro group where FED's of LUMO are high (Scheme 9). As for para position, FED of HOMO is also high, but the fact that no substitution is observed in the dark and the concurrent amination of ortho position are only explained by Rule 2 . This is consistent with the finding that upon irradiation of the $p$-chloronitrobenzene at -70 ${ }^{\circ} \mathrm{C}$ in ammonia, an ESR signal assigned to its radical anion

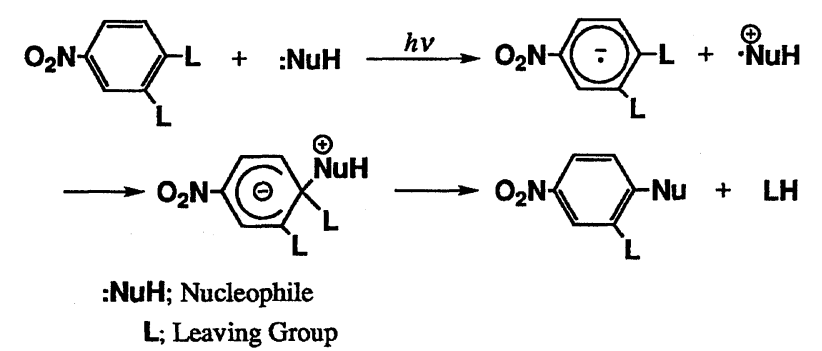

appears. $^{25)}$

These rules can be regarded as an extension of the electrontransfer mechanism proposed by Nagakura and Tanaka. ${ }^{76}$

Sophisticated Mechanism of Photorearrangement. Further study of the photoreaction of Scheme 7 revealed that the reaction of the lower two homologues is accelerated in the presence of base such as triethylamine or pyridine. ${ }^{34,77)}$ The base-catalysis is explained by generation of a second intermediate, anilide anion 4 (Scheme 10), through proton abstraction by the base from the cationic moiety of the radical ion pair; the anion in turn attacks at the ring carbon atom attached to the ether oxygen to form a spiro-Meisenheimer

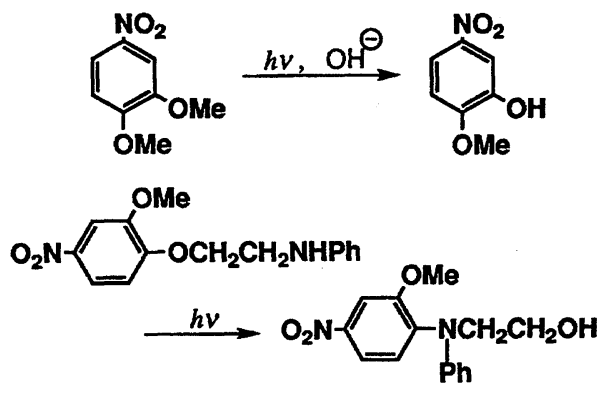

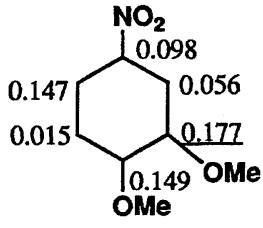

HOMO

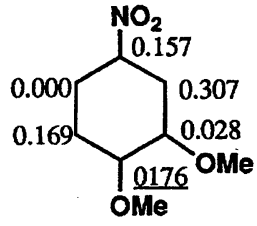

LUMO
Scheme 8. Photoreactions and frontier electron density maps (CNDO/2) of 3,4-dialkoxynitrobenzenes. ${ }^{25)}$

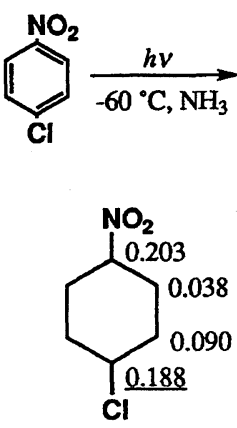

HOMO<smiles>Nc1cc(Cl)ccc1[N+](=O)[O-]</smiles><smiles>CC(C)C1CC(Cl)CCC1[N+](=O)[O-]</smiles>

LUMO
Scheme 9. Photoreaction and frontier electro density maps $(\mathrm{CNDO} / 2)$ of $p$-chloronitrobenzene. ${ }^{25)}$

Scheme 6.

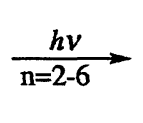

$\mathrm{O}_{2} \mathrm{~N} \longrightarrow-\left(\mathrm{CH}_{2}\right)_{n} \mathrm{NH} \longrightarrow$

$1 \lambda_{\max }\left(\mathrm{CH}_{3} \mathrm{CN}\right) 308 \mathrm{~nm}$
2 Radical ion pair

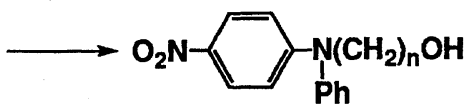

3

Scheme 7. 


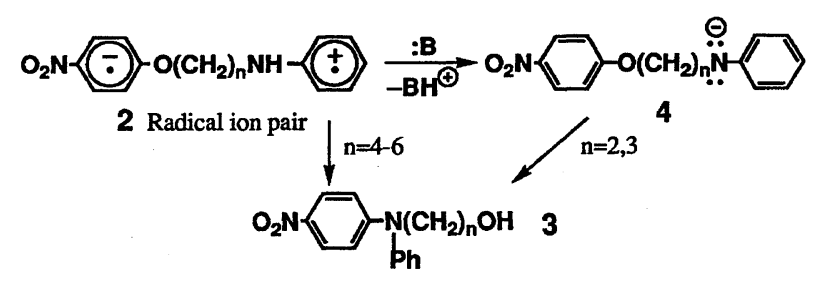

Scheme 10.

type complex. This mechanism is consistent with the fact that these lower homologues undergo the thermal rearrangement in the presence of a strong base such as sodium methoxide, giving the same product $\mathbf{3}$ as in the photoreaction. ${ }^{78)}$ In the higher homologues $(n=4-6)$, on the contrary, the effect of triethylamine is decelerating and pyridine is ineffective. ${ }^{34)}$ The deceleration is readily explained by a side reaction of the excited nitrophenoxy moiety abstracting hydrogen from $\mathrm{NCH}_{2}$ group of the catalyst amine, as is generally observed for the photoreaction of aromatic nitro compounds (vide infra). Pyridine lacks such an $\alpha$-hydrogen atom to be abstracted and failed to induce the side reaction. No catalytic effect of pyridine is consistent with the behavior of the higher homologues in the thermal reaction; that is, no thermal rearrangement was observed under the conditions generating the anilide anion. The incompetence of a base to catalyze the photorearrangement of the higher homologues suggests the presence of another rearrangement pathway. We conclude that this mechanism is a direct recombination of the radical ion pair to give a $\sigma$-complex which decomposes into the same type of rearrangement product (Scheme 10). There still remains the question about what the driving force can accomplish the medium-sized $\sigma$-complex ring formation exclusively from these far-separated radical ion pairs.

Another remarkable feature of the charge separation process is that it is a long range phenomenon observable even in the $n=12$ homologue. ${ }^{79,80}$ If one assumes through-space mechanism (intramolecular $\pi-\pi$ overlap of the acceptor and donor moieties or exciplex formation), this electron transfer is hard to understand, since the accessibility of the donor-acceptor pair such as intramolecular charge-transfer absorption spectrum is only observed for the $n=2$ and 3 homologues. ${ }^{81)}$
Here arises the through-bond electron-transfer mechanism; ${ }^{82)}$ that is, an electron is transferred through $\sigma$-bonds of the methylene chain. Supporting evidence for the through-bond mechanism is obtained by comparison of the relative quantum yields for the radical ion pairs generated in cyclohexane derivatives having an acceptor and a donor respectively fixed at 1 and 4-positions with those for the corresponding analogues with flexible chain Acceptor- $\left(\mathrm{CH}_{2}\right)_{n}$-Donor (Table 2). ${ }^{83)}$ The quantum yields for cyclohexane derivatives are much higher than those of their four-methylene chain counterparts; this reveals the high efficiency of the throughbond pathway. We assume that this mechanism is working in competition with a through-space process in the lower homologues and is dominant in the higher homologues. This photorearrangement is one of the rare cases of photoinduced through-bond charge separation leading to an intramolecular chemical reaction. The efficient intramolecular fluorescence quenching effect by $p$-nitrophenoxy group observed in a homologous series of $p-\mathrm{O}_{2} \mathrm{NC}_{6} \mathrm{H}_{4} \mathrm{O}\left(\mathrm{CH}_{2}\right)_{n} \mathrm{NH}-1-\mathrm{Naphthyl}$ ( $n=2-6)$ may be due to the same mechanism. ${ }^{84)}$

Methylene Chain Length Effects. The methylene chain length generally modulates the intramolecular reaction yield by governing the encounter probability of two reactive sites connected by a methylene chain. In other words, reaction yields of bifunctional chain species with structure $\mathrm{X}-\left(\mathrm{CH}_{2}\right)_{n}-\mathrm{Y}$ may critically depend upon the chain length $n$. Switching of reaction pathways due to methylene chain length effects has been reviewed by the present authors. ${ }^{85)}$ Scheme 11 shows that when the chain length is short $(n \leq 6)$, the photorearrangement predominates, while the long chain homologues $(n \geq 8)$ readily undergo photoredox reactions. ${ }^{79,80)}$ This is one of the clear-cut examples observed for nitro-aromatic species. The same kind of complete reaction switching has also been observed for naphthalene derivatives, $4-\mathrm{O}_{2} \mathrm{NC}_{10} \mathrm{H}_{6}-1-\mathrm{O}\left(\mathrm{CH}_{2}\right)_{n} \mathrm{NHPh}$ (Scheme 11). ${ }^{86)}$ If the low-lying $n, \pi^{*}$ and $\pi, \pi^{*}$ states are largely separated, the reaction switching may be more inefficient or less exclusive. Since they may be nearly degenerate, ${ }^{54)}$ reaction pathways for both photoredox and photosubstitution are accessible at room temperature.

Table 2. Relative Quantum Yields for Radical Ion Pair in Flexible and Rigid Model Compounds

\begin{tabular}{|c|c|c|c|}
\hline Compound & $\begin{array}{l}\text { Relative quantum } \\
\text { yield }^{\text {a) }}\end{array}$ & Compound & $\begin{array}{c}\text { Relative quantum } \\
\text { yield }^{\mathrm{a})}\end{array}$ \\
\hline$p-\mathrm{O}_{2} \mathrm{NC}_{6} \mathrm{H}_{4} \mathrm{O}\left(\mathrm{CH}_{2}\right)_{n} \mathrm{NHPh}$ & & $1-\left(p-\mathrm{O}_{2} \mathrm{NC}_{6} \mathrm{H}_{4} \mathrm{O}\right)-\mathrm{Cyc}-4-\mathrm{NHPh}^{\mathrm{b})}$ & \\
\hline$n=2$ & 1.00 & & \\
\hline$n=3$ & 1.29 & Cis & 1.99 \\
\hline$n=4$ & 1.08 & Trans & 1.55 \\
\hline$n=5$ & 0.65 & & \\
\hline$n=6$ & 0.32 & & \\
\hline$p-\mathrm{O}_{2} \mathrm{NC}_{6} \mathrm{H}_{4} \mathrm{O}\left(\mathrm{CH}_{2}\right)_{n} \mathrm{OC}_{6} \mathrm{H}_{4} \mathrm{NMe}_{2}-p$ & & $1-\left(p-\mathrm{O}_{2} \mathrm{NC}_{6} \mathrm{H}_{4} \mathrm{O}\right)-\mathrm{Cyc}-4-\left(\mathrm{OC}_{6} \mathrm{H}_{4} \mathrm{NMe}_{2}-p\right)^{\mathrm{b})}$ & \\
\hline$n=2$ & 1.75 & & \\
\hline$n=3$ & 0.99 & Cis & 1.56 \\
\hline$n=4$ & 0.90 & Trans & 1.37 \\
\hline$n=6$ & 0.38 & & \\
\hline
\end{tabular}

a) In acetonitrile. The absorbance of the radical ion pair of $p-\mathrm{O}_{2} \mathrm{NC}_{6} \mathrm{H}_{4} \mathrm{O}\left(\mathrm{CH}_{2}\right)_{2} \mathrm{NHPh}$ is set as a standard. b) Cyc = Cyclohexane. 

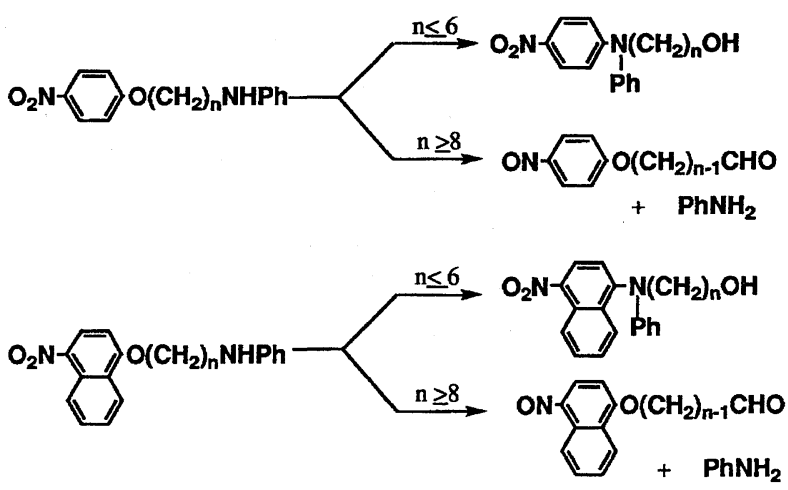

Scheme 11 .

When the chain length is sufficiently large, chemical behavior of the long-chain molecules, $\mathrm{X}-\left(\mathrm{CH}_{2}\right)_{n}-\mathrm{Y}(n \geq 8)$ is generally related with that of the intermolecular reaction between $\mathrm{X}-\mathrm{CH}_{3}$ and $\mathrm{H}_{3} \mathrm{C}-\mathrm{Y}$. For instance, photochemical behavior of the long chain homologues of $\mathbf{1}$ is very similar to that of the corresponding analogue consisting of $p$ nitroanisole and $N$-alkylaniline. ${ }^{79)}$ The end products of this intermolecular photochemistry have been identified as $p$-nitrosoanisole and aniline, and no substitution product corresponding to compound 3 (Scheme 10) has been obtained. ${ }^{79)}$ Photo-oxidative demethylation has been observed for similar reaction systems. ${ }^{87)}$ From these findings, the photorearrangement of 1 should be regarded as a forced intramolecular nucleophilic photosubstitution. The different reactivity observed for the short- and long-chain species can be explained in terms of the encounter probability for both end groups (X and $\mathrm{Y}$ ) with conformations pertinent to product formation.

\section{Intermolecular Photoredox Reactions}

Photoredox reactions of nitrobenzenes have been reviewed according to the experimental conditions, namely, acidic, neutral, and basic solutions. ${ }^{42,48)}$ There may be two different reaction pathways for photoredox processes: (1) electron transfer and (2) hydrogen abstraction. The former is favored in highly polar solvents, e.g. acidic and alkaline media, while the latter is favored in neutral alcoholic media. There has been reason to believe that in highly polar media the reaction proceeds with the initial electron transfer followed by proton transfer. ${ }^{48)}$ In both cases radical species are produced on photolysis. Oxidation of alcohols to carbonyl compounds proceeds stepwise: the first stage is the formation of $\alpha$-hydroxyalkyl radical from the alcohol, and the second stage is dehydrogenation of the hydroxyalkyl radical to yield the end product with carbonyl moiety. Although the mechanism of interaction of the hydroxyalkyl radicals and nitro-aromatic species is more complicated than expected on the basis of single electron transfer between the reactants, ${ }^{88)}$ the overall redox yield is governed primarily by the reactivity of both dehydrogenation processes.

Photoredox reaction yields for $p-\mathrm{X}-\mathrm{C}_{6} \mathrm{H}_{4} \mathrm{NO}_{2}$ can be correlated with the electron-donating ability of $\mathrm{X}^{89-91)}$ When $\mathrm{X}$ is highly electron-donating, the lowest excited triplet state is dominantly of intramolecular charge-transfer character. For example, $p$-nitroaniline is not much reduced on irradiation. Table 3 shows that the quantum yield decreases with increasing electron-donating ability of $X$. This indicates that the increase in intramolecular charge-transfer character of $T_{1}$ is responsible for inefficient photoreduction. In other words, the redox reactivity increases with increasing $\mathrm{n}, \pi^{*}$ character. It is to be noted that $N, N$-dimethyl-p-nitroaniline undergoes no reaction on photoexcitation in the presence of sodium borohydride. Upon irradiation, $m$-nitroanisole is reduced to $m$-anisidine in diethylamine solvent, ${ }^{92)}$ while it is converted to nitrobenzene in the presence of sodium borohydride. ${ }^{93}$ There has been a noticeable correlation between rate constants of para-substituted nitrobenzenes $p-\mathrm{X}-\mathrm{C}_{6} \mathrm{H}_{4} \mathrm{NO}_{2}$ with $\alpha$-hydroxyalkyl radicals and the electron-donating ability of substituent $\mathrm{X}^{88)}$ This means that nitrobenzenes with higher electron affinity readily oxidize the hydroxyalkyl radical.

Reactivity of the lowest excited triplet state can be summarized as follows:

1. An efficient hydrogen abstraction takes place when the $T_{1}$ state is dominantly of $n, \pi^{*}$ character.

2. When the $T_{1}$ state is characterized as $\pi, \pi^{*}$ state, both redox and substitution reactions may be observed in the presence of appropriate reducing and nucleophilic reagents.

3. Neither redox nor substitution takes place from the intramolecular charge-transfer triplet state. ${ }^{94)}$ Since the intramolecular charge-transfer state has lower transition energy than the $n, \pi^{*}$ or $\pi, \pi^{*}$ transition, it can serve as a weaker electron acceptor.

\section{External Magnetic Field Effects on Intramolecular Photoredox Reaction Yields}

Origin of Magnetic Field Effects. Nagakura and collaborators have developed a general theory of the radical pair (RP) model in order to interpret anomalous ESR spectra observed for $\mathrm{X}$ - or $\gamma$-ray irradiated organic single crystals. ${ }^{95)}$ They showed that the singlet-triplet mixing can be induced by hyperfine coupling and the electronic Zeeman mechanism. This RP model has been playing a central role in explaining electron and nuclear polarization induced by chemical reactions (CIDEP and CIDNP). ${ }^{96-99)}$ This model also pro-

Table 3. Quantum Yield for Photoreduction of Nitrobenzenes $p-\mathrm{X}-\mathrm{C}_{6} \mathrm{H}_{4} \mathrm{NO}_{2}$ in 2-Propanol

\begin{tabular}{lcc}
\hline \multicolumn{1}{c}{$\mathrm{X}$} & $\begin{array}{c}\text { Quantum yield, } \\
\text { from Ref. 90 }\end{array}$ & $\begin{array}{c}\text { Quantum yield, } \\
\text { from Ref. 91 }\end{array}$ \\
\hline $\mathrm{NO}_{2}$ & 0.16 & \\
$\mathrm{CN}$ & $0.48^{\mathrm{b})}$ & \\
$\mathrm{COOC} \mathrm{H}_{5}$ & 0.15 & \\
$\mathrm{COOCH}\left(\mathrm{CH}_{3}\right)_{2}$ & 0.15 & \\
$\mathrm{COOH}$ & 0.12 & 0.0114 \\
$\mathrm{H}$ & 0.03 & 0.039 \\
$\mathrm{CH}_{3}$ & 0.07 & \\
$\mathrm{OCH}_{3}$ & 0.02 & \\
$\mathrm{OH}$ & 0.00 & 0.00072 \\
$\mathrm{NH}_{2}$ & 0.004 & \\
\hline
\end{tabular}

a) Quantum yield for the reactant disappearance unless otherwise indicated. b) Quantum yield for the product formation. 
vides a theoretical basis for magnetic field effects on reaction rates and product yields of chemical reactions involving radical pairs or biradicals. ${ }^{99-101)}$ A simple vector model for $\mathrm{RP}$ is introduced to explain the mechanism by which nuclearspins can operate to influence the intersystem crossing (ISC) rate for the RP; the physical interactions responsible for this triplet-singlet conversion are also considered in this section. The vector model of electron spins in a RP is shown in Scheme 12. ${ }^{100)}$ Let the $z$ axis correspond to a direction defining the orientation of the spin vectors. There are three sublevels of the triplet state $\left(\mathrm{T}_{+}, \mathrm{T}_{0}\right.$, and $\left.\mathrm{T}_{-}\right)$distinguishable by their values of $z$-component of $\operatorname{spin}\left(s_{z}=+1,0,-1\right)$. The $z$ component is zero in the singlet sate. The energy separation between the singlet and triplet states $(\Delta E)$ is designated by $2 J$, where $J$ is the energy of exchange interaction of two unpaired electrons. When $J$ is negligibly small in comparison with the hyperfine interaction, ISC is energetically allowed (Scheme 13(a)). The magnitude of $J$ is strongly dependent on the distance between the radical centers; the degeneracy is virtually realized when they are separated by about $1 \mathrm{~nm}$ or longer. In the absence of a magnetic field, triplet sublevels are degenerate. An external magnetic field removes the degeneracy and splits these sublevels by the value of the Zeeman energy, $g \beta H$ (Scheme 13(b)). The triplet-singlet conversion of a radical pair requires the change of electron spin, and this change must be compensated by the appropriate modification of nuclear spins. The coupling between these spin systems, electronic and nuclear, is realized through the hyperfine interaction. Two different mechanisms for ISC are suggested by the vector model of the singlet and triplet states: (1) a spin rephasing mechanism by which $T_{0}$ and $S$ can be
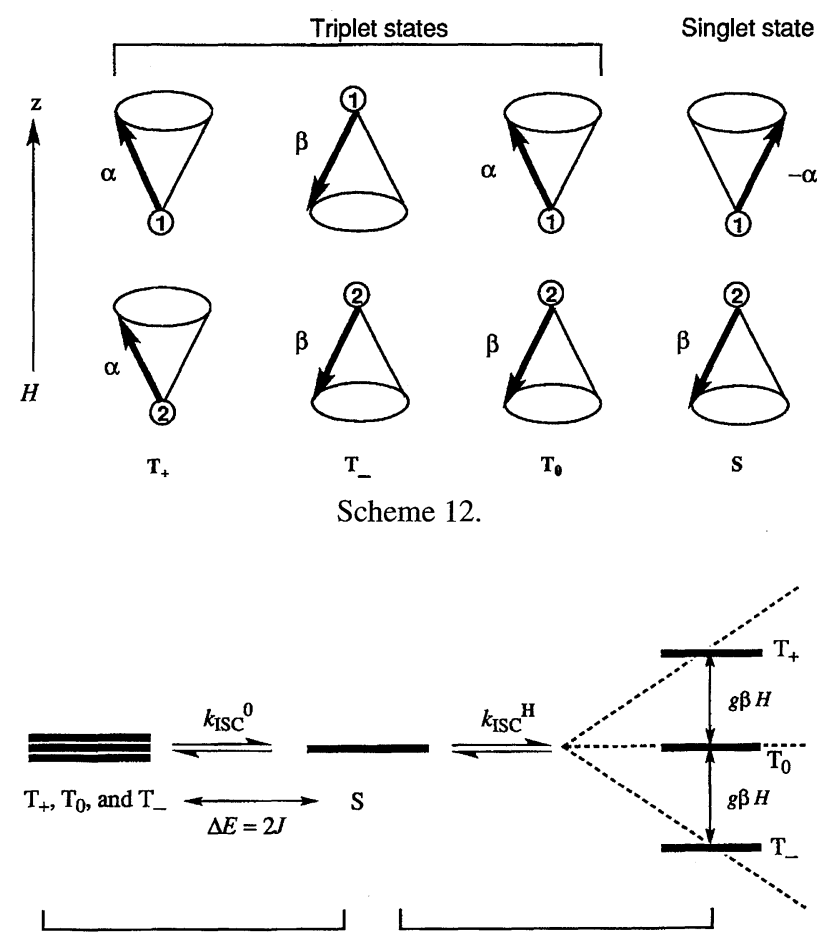

(a) $H=0$

(b) $H \neq 0$ interconverted. (2) a spin-flip mechanism by which $\mathrm{T}_{+}$(or $\mathrm{T}_{-}$) and $\mathrm{S}$ may be interconverted. If the local magnetic field is along the $z$-direction, the relative rephasing occurs through precession about the $z$-direction and the singlet state switches into the $\mathrm{T}_{0}$ sublevel. If the local field lies in the $x y$ plane, the field can provide a torque to twist one of the spins and cause it to flip. Namely, one of the spins in $\mathrm{T}_{+}$(or $\mathrm{T}_{-}$) is changed from $\alpha$ to $\beta$ (or $\beta$ to $\alpha$ ), leaving the other unaffected. In the presence of external magnetic fields larger than the hyperfine interaction by one order of magnitude, only the ISC process between $T_{0}$ and $S$ is accessible, because the ISC between $T_{+}$(or $T_{-}$) and $S$ is blocked by the energy difference proportional to the magnetic field strength.

Scheme 14 shows a kinetic scheme for biradical reactions of triplet precursor. Suppose that the lowest excited triplet state is involved in the photoreaction. The biradical intermediate derived from the $T_{1}$ state is also in the triplet manifold. The triplet biradical cannot yield a stable singlet product without ISC to the singlet biradical. The singlet-triplet interconversion is thus suppressed by the external magnetic field when the hyperfine coupling is of dominant importance. Cage products can be formed from the intramolecular reaction of the singlet biradical. In contrast, the triplet biradical may encounter a parent molecule in the ground state and undergo a bimolecular redox reaction. Escape products are formed through this intermolecular process. The competition between the intra- and intermolecular photoredox reactions is dependent on the applied field strength, because the ISC between the singlet and triplet biradicals is sensitive to the magnetic field.

The energy separation of triplet sublevels for ordinary organic radicals induced by the external magnetic field of $1 \mathrm{~T}$ is approximately equal to $1 \mathrm{~cm}^{-1}$ or $11 \mathrm{~J} \mathrm{~mol}^{-1}$. Typical hyperfine coupling constants are of the order of $0.1-2 \mathrm{mT}$ (ca. $10^{-4}$ or less than $2 \times 10^{-3} \mathrm{~J} \mathrm{~mol}^{-1}$ ). Evidently the external magnetic field of $1 \mathrm{~T}$ only slightly affects the nature of electronic states, energy barriers or equilibrium constants of reaction systems. Hence the magnetic field effect is an effect not on the energy term $E_{\mathrm{a}}$, but on the frequency factor $A$ of the Arrhenius equation, $k=A \exp \left(-E_{\mathrm{a}} / R T\right)$.

Magnetic Field Effects on Product Yields. There have been a number of papers which report dynamical behavior of biradical intermediates generated on photolysis of bichromophoric chain molecules and cyclic ketones in the presence of an external magnetic field. ${ }^{19)}$ Magnetic field effects (MFE) on lifetimes of radical pairs or biradicals have been detected by means of nanosecond laser photolysis. The decay profiles of these species are found to depend upon rates of several

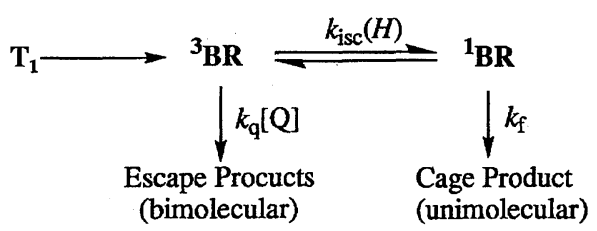

BR=biradical

Scheme 14.

Scheme 13. 
processes, e.g. geminate recombination, ISC, spin-lattice relaxation, and chain dynamics. On the other hand, MFE on the end product yield are relatively difficult to observe, because competition between the cage and the escape product formation is necessary. If the intermolecular escape reaction rate is completely absent, there may be no MFE on the end product yield. MFE on the reaction yields have not been so extensively studied as those on the decay time of reaction intermediates.

Appreciable external MFE on product yields have been observed for photoredox reactions involving biradical intermediates derived from bichromophoric chain molecules with the structure of $\mathrm{NA}-\mathrm{O}\left(\mathrm{CH}_{2}\right)_{n}-\mathrm{NHPh}$ where $\mathrm{NA}=p$ $\mathrm{O}_{2} \mathrm{NC}_{6} \mathrm{H}_{4}-$ or $4-\mathrm{O}_{2} \mathrm{NC}_{10} \mathrm{H}_{6}-1-$ and $n \geq 8 .^{86,102-107)}$ Two independent reaction pathways have been identified as cage and escape processes. The cage process is characterized as an intramolecular oxidative dealkylation of substituted aniline, coupled with deoxygenation of the nitro group, while the escape process is a bimolecular dealkylation involving the triplet biradical and the starting species in the ground state. Scheme 15 illustrates the cage and escape products in photoreaction of $p$-nitrophenoxy derivatives.

One of the simplest way to detect MFE is to compare the changes in absorption spectra of the solutions irradiated in the absence and presence of an external magnetic field. A typical example is shown in Fig. 1 for the photoreaction of $p-\mathrm{O}_{2} \mathrm{NC}_{6} \mathrm{H}_{4} \mathrm{O}\left(\mathrm{CH}_{2}\right)_{12} \mathrm{NHPh}(1, n=12)$. The increase in absorbance at $345 \mathrm{~nm}$ (Fig. 1) is due to the formation of $p$-nitrosophenoxy chromophore. Comparison of Fig. 1a with Fig. 1b shows that the production of 5 (Scheme 15) is reduced in the presence of an external magnetic field. Figure 2 illustrates chromatograms recorded after photolysis in the absence and presence of an external magnetic field $(0.64 \mathrm{~T})$. This figure clearly shows that cage product 5 yield decreases and escape products (6 and 7) yields increase on application of the magnetic field. MFE on the end product yields are listed in Table 4.

On the basis of all these findings, we have proposed a photoredox mechanism (Scheme 16); ${ }^{107)}$ an excited triplet aromatic nitro group abstracts a hydrogen atom from the $\mathrm{CH}_{2}$ group adjacent to the anilino moiety, producing a triplet

Table 4. Magnetic Field Effects upon Product Formation $\left(I^{\mathrm{H}} / I^{0}\right)$ for Photochemistry of $p-\mathrm{O}_{2} \mathrm{NC}_{6} \mathrm{H}_{4} \mathrm{O}$ $\left(\mathrm{CH}_{2}\right)_{12} \mathrm{NHPh}$ in Benzene ${ }^{\mathrm{a})}$

\begin{tabular}{|c|c|c|c|}
\hline \multirow[t]{2}{*}{$\overline{\text { Product }^{b)}}$} & \multirow[t]{2}{*}{$I^{\mathrm{H}} / I^{0 \mathrm{c})}$} & \multirow[t]{2}{*}{ Formation process $^{\text {d) }}$} & \multirow{2}{*}{$\frac{\text { Wavelength }^{\mathrm{e})}}{\mathrm{nm}}$} \\
\hline & & & \\
\hline 5 & $0.82 \pm 0.02$ & (Cage process) MCO & 345 \\
\hline 6 & $1.43 \pm 0.05$ & (Escape process) $\mathrm{MCO}$ & 310 \\
\hline 7 & $1.39 \pm 0.05$ & (Escape process) NDO & 345 \\
\hline Aniline & \multicolumn{2}{|c|}{$\begin{array}{c}1.00 \pm 0.03 \text { (Cage and escape processes) } \\
\mathrm{MCO}\end{array}$} & 300 \\
\hline
\end{tabular}

a) All data are taken from Ref. 105 . b) Structures of products 5 , 6, and 7 are shown in Scheme 15 . c) $I^{\mathrm{H}}$ and $I^{0}$ refer to peak areas in the chromatograms recorded after photolysis in the presence and absence, respectively, of an external magnetic field $(0.64 \mathrm{~T})$. The quoted uncertainty represents the standard deviation. d) MCO indicates the site of oxidation, namely, methylene chain oxidation. Nitro to nitroso deoxygenation is designated by NDO. e) Monitoring wavelength for HPLC analysis.

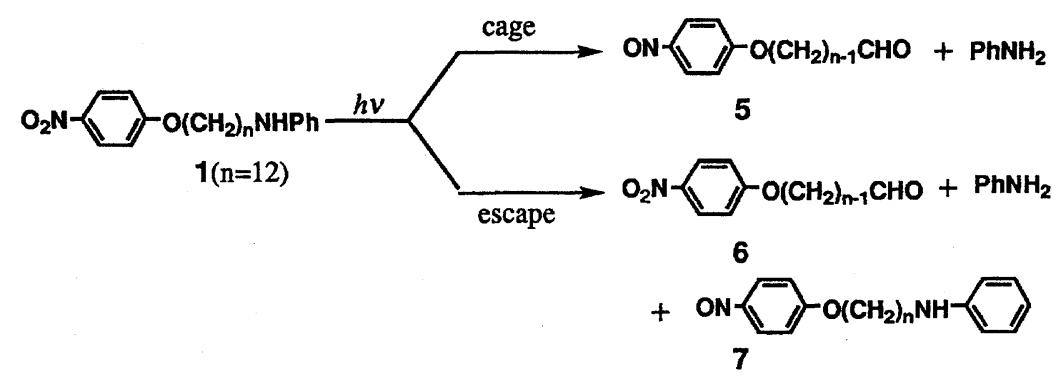

Scheme 15 .
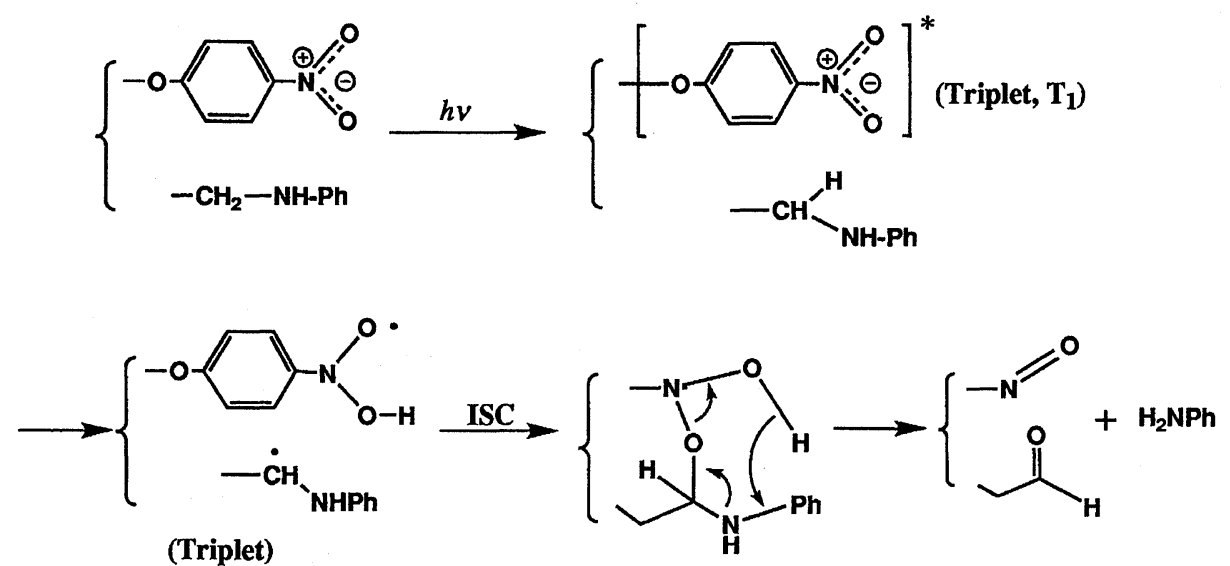

Scheme 16. 


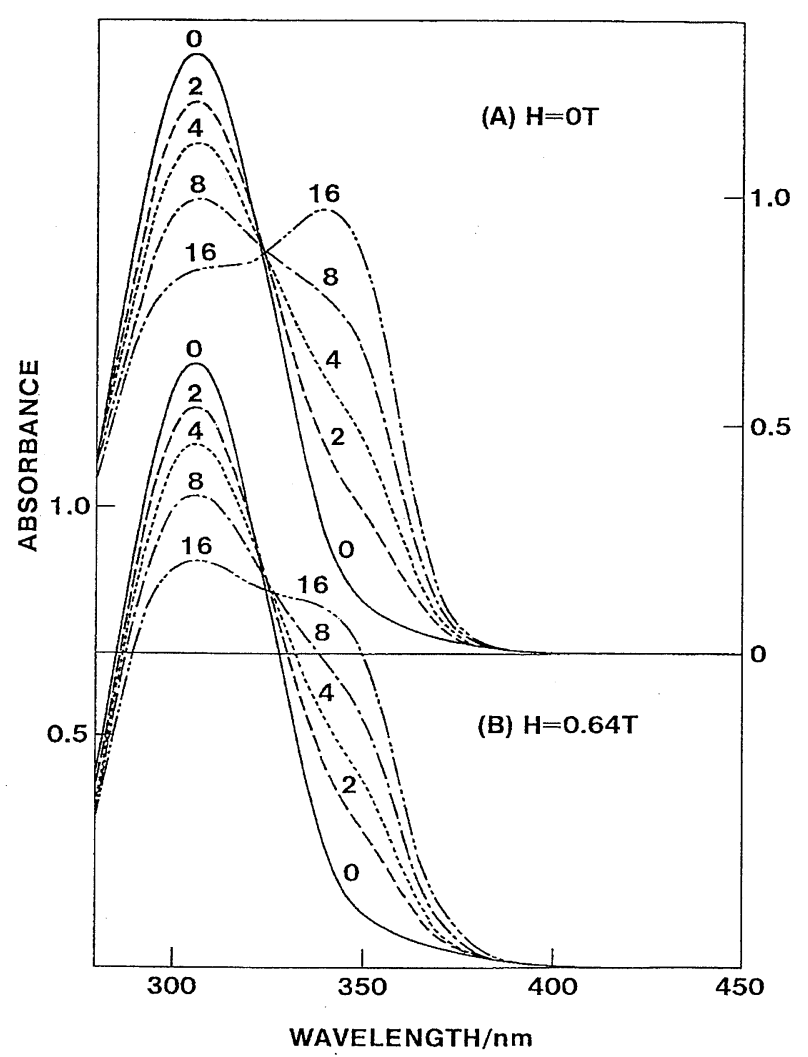

Fig. 1. Development of photoredox reaction of $p$ $\mathrm{O}_{2} \mathrm{NC}_{6} \mathrm{H}_{4} \mathrm{O}\left(\mathrm{CH}_{2}\right)_{12} \mathrm{NHPh}$ in benzene as revealed by uv absorption spectroscopy (A) in zero field and (B) in the presence of $0.64 \mathrm{~T}$. The number refers to the irradiation time in min. Excitation source: $500 \mathrm{~W}$ Xe are filtered through a combination of color glass filters (Hoya U-340, Toshiba UV-25, and Toshiba UV-30). Data taken from Ref. 107.

radical pair which through ISC forms a transient heterocycle and subsequently decomposes into the cage products. This ISC is the step that undergoes magnetic field effects.

Relaxation Model. Figure 3 indicates that photoinduced changes in absorbance gradually decrease as the magnetic field strength increases and these changes saturate in a high field region. This kind of magnetic field dependence cannot be explained in terms of a simple model considering hyperfine interaction only. The kinetic analysis of MFE on decay profile has clarified that the spin-lattice relaxation may play an important role in the high field region. ${ }^{108-113)} \mathrm{A}$ kinetic model including the spin-lattice relaxation is shown in Scheme 17. ${ }^{114)}$ We can evaluate the magnitude of MFE on cage product formation by the use of this Scheme 17, on the following assumptions:

1. The three sublevels of the triplet biradicals are equally populated from the molecular excited triplet state.

2 . The spin-lattice relaxation rate $\left(k_{\mathrm{rlx}}\right)$ and bimolecular escape reaction rate $\left(k_{\mathrm{q}}[\mathrm{Q}]\right)$ are much slower than intersystem crossing rate $\left(k_{\mathrm{ST}}\right)$, populating rate $\left(k_{\mathrm{p}}\right)$, or product formation rate $\left(k_{\mathrm{f}}\right)$.

3. The reactivity of the sublevel is the same for $T_{+}$and $\mathrm{T}_{\text {-. }}$. The ratio of quantum yields in the presence and absence

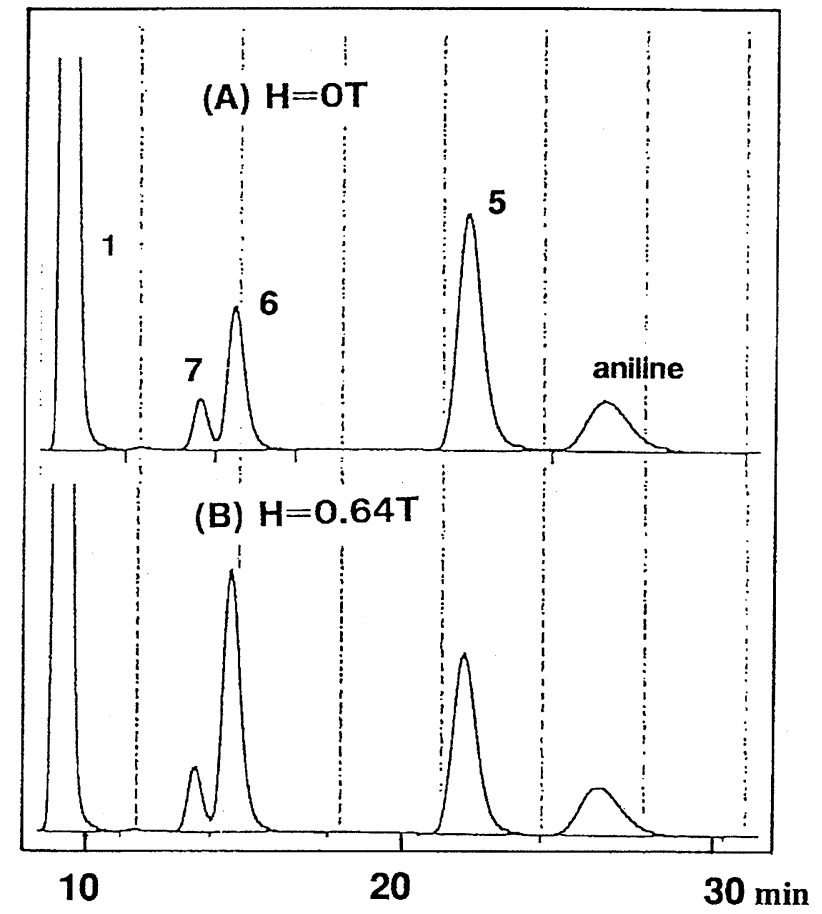

Fig. 2. High-performance liquid chromatogram of the irradiated benzene solution of $p-\mathrm{O}_{2} \mathrm{NC}_{6} \mathrm{H}_{4} \mathrm{O}\left(\mathrm{CH}_{2}\right)_{12} \mathrm{NHPh}(8$ $\mathrm{min})$. (A) in the absence and (B) presence of an external magnetic field $(0.64 \mathrm{~T})$. Normal-phase column, Cica-Merck LiChrosorb Si $60(10 \mu \mathrm{m})$. Eluent: benzene : THF $=100: 1$. Absorbance monitored at $300 \mathrm{~nm}$. Initial concentration of the starting material is $1.0 \times 10^{-4} \mathrm{~mol} \mathrm{dm}^{-3}$. For the structures of the compounds numbered 1, 5, 6, and 7 see Scheme 15. Data taken from Ref. 107.

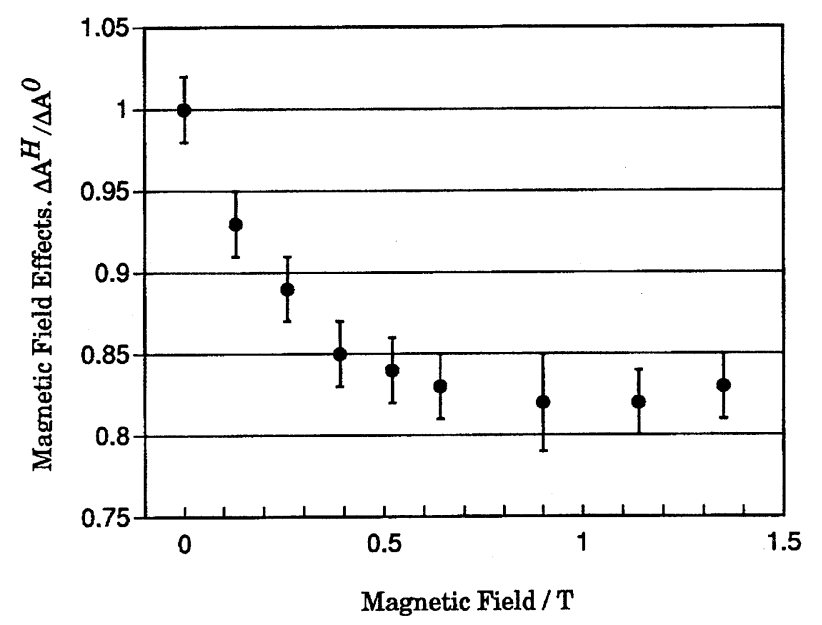

Fig. 3. Magnetic field effects on absorbance change ratio, $\Delta A^{\mathrm{H}} / \Delta A^{0}$, where $\Delta A^{\mathrm{H}}$ and $\Delta A^{0}$ refer to the absorbance change at $345 \mathrm{~nm}$ in the presence and absence of $0.64 \mathrm{~T}$ after 2 min photolysis. The irradiation conditions are essentially the same as those for Fig. 1.

of an external magnetic field is evaluated on the assumptions above, which can be summarized as follows:

$$
\begin{aligned}
\left(\Phi^{\mathrm{H}} / \Phi^{0}\right) & =1 / 3+(2 / 3)\left\{2 k_{\mathrm{rlx}} /\left(2 k_{\mathrm{rlx}}+k_{\mathrm{q}}[\mathrm{Q}]\right\}\right. \\
& =(1 / 3)\{(3+x) /(1+x)\},
\end{aligned}
$$




\section{ACCOUNTS}

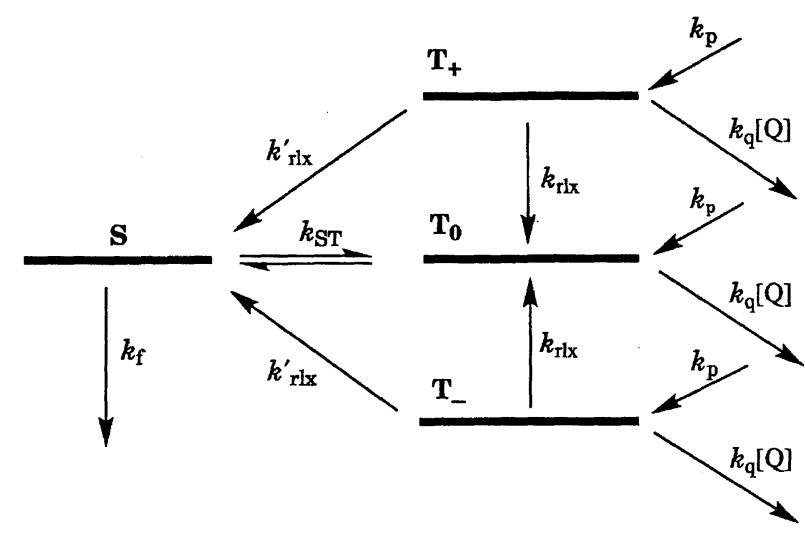

Scheme 17.

where $x=k_{\mathrm{q}}[\mathrm{Q}] / 2 k_{\mathrm{rlx}}$.

When the inter-radical distance is sufficiently long, i.e. the number of methylene groups is more than ten, the ISC rate in the zero field is rather large (ca. $10^{8} \mathrm{~s}^{-1}$ ). It is generally expected that spin-lattice relaxation or bimolecular escape reaction may be much slower than product formation or biradical formation (hydrogen abstraction). Consequently, the reactivity of two sublevels, $T_{+}$and $T_{-}$, is completely different from that of $\mathrm{T}_{0}$. With the aid of Eq. 1, we can evaluate the relative importance of the escape process, $x$, from the observed MFE on end product yields. The magnitude of $x$ is evaluated to be in the range of $0.03-0.4$. Spin-lattice relaxation rates observed for organic radicals are typically of the order of $10^{5} \mathrm{~s}^{-1}$. Since $k_{\mathrm{q}}$ is of the order of $10^{8}$ $10^{9} \mathrm{~mol}^{-1} \mathrm{dm}^{3} \mathrm{~s}^{-1}$, the product $k_{\mathrm{q}}[\mathrm{Q}]$ may be in the range of $10^{4}-10^{5} \mathrm{~s}^{-1}$ when $[\mathrm{Q}]=10^{-4} \mathrm{~mol} \mathrm{dm}^{-3}$. The estimation in this manner $\left(x=10^{-1}-10^{-2}\right)$ is in agreement with the values derived from observed ratios $\left(\Phi^{\mathrm{H}} / \Phi^{0}\right)$. If the parameter $x$, suitable for describing competitive processes, is zero, there may be no MFE on the end product yield. In other words, the magnitude of MFE on the end product yields is governed by the competition between the spin-lattice relaxation and the bimolecular escape process. When $p$-nitrophenoxy chromophore is employed as the oxidant moiety, the bimolecular escape reactivity is related to the oxidation potential of re- ductant moiety in biradical intermediates.

Chain Length and Magnetic Field Effects on Product Distributions. Scheme 18 illustrates photo-induced intramolecular long range oxygen transfer reactions for a series of nitro-aromatic derivatives. ${ }^{86,102-107,115)}$ Product yields of these reactions are dependent on the magnetic field strength and methylene chain length. Magnetic field and chain length effects have been extensively studied for $p$-nitrophenoxy and 4-nitro-1-naphthyloxy derivatives. No magnetic field effects were observed for the nitrophenoxy series with $n \leq 7$ (see Fig. 4). This fact can be interpreted in terms of the magnitude of exchange interaction, $J$. The magnitude of $J$ can be estimated by an exponential function:

$$
J(r)=J_{0} \exp (-a r),{ }^{116)}
$$

where $r$ is the inter-radical distance, and $J_{0}$ and a are constants inherent to the system. When the chain length is shorter than 7 , the magnitude of $J$ may not be small enough in comparison with the hyperfine interaction. The nitronaphthyloxy derivatives constitute an example of switching of reaction pathways

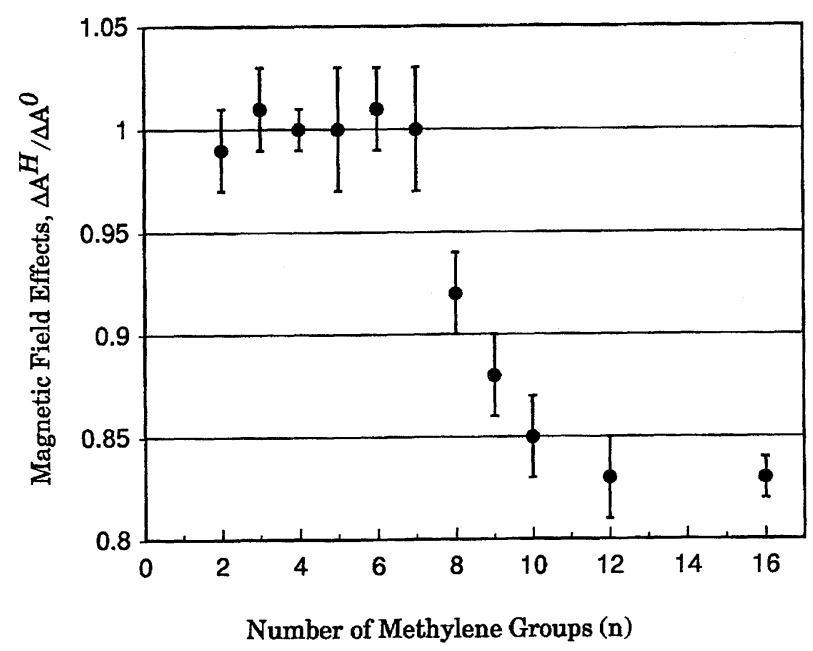

Fig. 4. Magnetic field effects on absorbance change ratio as a function of chain length. The irradiation conditions are essentially the same as those for Fig. 3 .

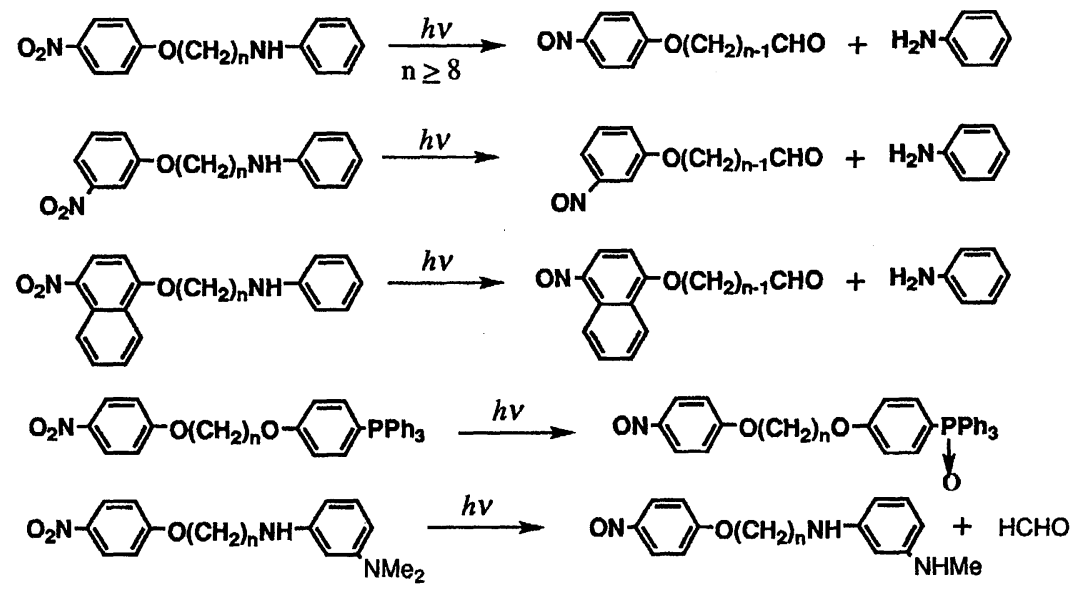

Scheme 18. Intramolecular photoredox reactions. 
Table 5. Magnetic Field Effects on Product Distribution for 4-Nitro-1-naphthyloxy- $\left(\mathrm{CH}_{2}\right)_{n} \mathrm{NHPh}$ in Benzene

\begin{tabular}{ccccccc}
\hline \multirow{2}{*}{$\begin{array}{c}\text { Methylene chain } \\
\text { Length } n\end{array}$} & \multicolumn{2}{c}{ Zero Field } & & \multicolumn{2}{c}{$0.64 \mathrm{~T}$} & Relative \\
\cline { 2 - 3 } & $\mathrm{C}^{\mathrm{a}} / \%$ & $\mathrm{E}^{\mathrm{b})} / \%$ & & $\mathrm{C}^{\mathrm{a})} / \%$ & $\mathrm{E}^{\mathrm{b}} / \%$ & Reactivity \\
\hline 8 & $61 \pm 2$ & $39 \pm 3$ & & $37 \pm 2$ & $63 \pm 4$ & 0.26 \\
9 & $71 \pm 2$ & $29 \pm 2$ & & $47 \pm 2$ & $53 \pm 4$ & 0.55 \\
10 & $81 \pm 2$ & $19 \pm 1$ & & $52 \pm 2$ & $48 \pm 3$ & 1.00 \\
11 & $82 \pm 2$ & $18 \pm 1$ & & $59 \pm 2$ & $41 \pm 3$ & 0.97 \\
12 & $76 \pm 2$ & $24 \pm 2$ & & $54 \pm 2$ & $46 \pm 3$ & 1.30 \\
\hline
\end{tabular}

a) $\mathrm{C}$ denotes cage product (corresponds to product 5 in Scheme 15). b) $\mathrm{E}$ denotes escape product (corresponds to product 6 in Scheme 15).

Table 6. Solvent Effects on Product Distribution for 4-Nitro-1-naphthyloxy- $\left(\mathrm{CH}_{2}\right)_{12} \mathrm{NHPh}$

\begin{tabular}{cccccc}
\hline Solvent & \multicolumn{2}{c}{ Zero Field } & & \multicolumn{2}{c}{$0.64 \mathrm{~T}$} \\
\cline { 2 - 3 } \cline { 6 - 6 } \cline { 5 - 6 } & $\mathrm{C}^{\mathrm{a})} / \%$ & $\mathrm{E}^{\mathrm{b})} / \%$ & & $\mathrm{C}^{\mathrm{a})} / \%$ & $\mathrm{E}^{\mathrm{b})} / \%$ \\
\hline Benzene & $76 \pm 2$ & $24 \pm 2$ & & $54 \pm 2$ & $46 \pm 3$ \\
Acetonitrile & $63 \pm 2$ & $37 \pm 2$ & & $51 \pm 2$ & $49 \pm 3$ \\
DMF- $\mathrm{H}_{2} \mathrm{O}^{\mathrm{c})}$ & $77 \pm 2$ & $23 \pm 2$ & & $62 \pm 2$ & $38 \pm 3$ \\
DMF- $\mathrm{H}_{2} \mathrm{O}-\gamma-\mathrm{CD}^{\mathrm{d})}$ & $66 \pm 2$ & $34 \pm 2$ & & $45 \pm 2$ & $55 \pm 3$ \\
\hline
\end{tabular}

a) $\mathrm{C}$ denotes cage product. b) $\mathrm{E}$ denotes escape product. c) DMF-water mixed solvent ( $80: 20$ by volume ratio). $\mathrm{DMF}=N, N$-dimethylformamide. d) $\mathrm{DMF}$-water mixed solvent ( $80: 20$ by volume ratio containing $6.9 \times 10^{-3} \mathrm{M}$ of $\gamma$-cyclodextrin $(\gamma-\mathrm{CD}))$.

due to chain length and magnetic field effects. The product distribution of the nitronaphthyloxy series was recorded by changing the chain length in the absence and presence of an external magnetic field. When the chain length is shorter than 7, photorearrangement predominates, whereas the photoredox reaction is observed for long chain homologues. At the particular chain length of $n=8$, the major process in zero field is the intramolecular photoredox reaction, while the bimolecular escape reaction predominates in a high field, 0.64 T. For longer chain species $(n \geq 9)$, the intramolecular cage process is always dominant irrespective of the field strength. Table 5 shows the relative reactivity and the product distribution observed for photoreactions of the nitronaphthyloxy species as a function of chain length. Table 6 also illustrates that the cage and escape product distribution critically depends upon the nature of solvents used in the presence of $0.64 \mathrm{~T}$. Extremely small interactions such as the Zeeman energy and hyperfine interaction can give rise to a remarkable change in the distribution of end products derived from photoredox reactions for bifunctional chain molecules. There has been progress in the elucidation of reaction mechanism through the analysis of MFE on product yields for chemical reactions involving radical pairs or biradicals.

\section{Concluding Remarks}

Photo-induced reactions of nitro and carbonyl compounds have attracted attention among photochemists. The synthetic and mechanistic studies of carbonyl photochemistry have now matured to the stage that practicing chemists can pre- dict photophysical and photochemical properties with some confidence. Although the early results in nitro-aromatic photochemistry have been followed up with some interest, the mechanistic aspects have not been clarified until recently. There has been a remarkable progress in scientific instrumentation which permits the time-resolution in the picosecond range. ${ }^{117)}$ Thus, transient species in photoreactions are fairly easily detected and identified. Nevertheless, there are a number of unanswered questions.

The nature of low-lying excited states of nitro-aromatic compounds has been well characterized by analyzing spectroscopic data with the aid of molecular orbital calculations. In contrast, photochemical properties have not been fully understood in terms of molecular orbital parameters for the excited nitro-aromatic species and the reducing or nucleophilic reagents. At least, orientations in photochemical nucleophilic substitutions can be predicted on the basis of molecular orbital analysis for nitro-aromatic compounds in the excited state. A firm structure-reactivity relationship should be experimentally established before systematizing theoretical interpretation based upon molecular orbital calculations.

Our major contributions to the nitro-aromatic photochemistry are summarized as follows:

1. Explanation of anomalous nucleophilic photosubstitution regioselectivities with respect to the nitro group.

2. Discovery of complete reaction switching due to methylene chain length effects from the photorearrangement to the photoredox reaction.

3. Magnetic field modulation of the end product yield in photoredox reactions for methylene-linked chain molecules containing nitro-aromatic chromophore and anilino moieties.

Our findings may provide more insights into intra- and intermolecular photochemistry of nitro-aromatic species.

Most of our studies cited in this account were supported by the Joint Study Program of the Institute for Molecular Science and Grant-in-Aid for Scientific Research on Priority Areas "Molecular Design" (No. 02230228) and "Molecular Magnetism" (Area No. 228/04 242 107) from the Ministry of Education, Science, Culture and Sports. We thank Professor Y. Tanimoto (Hiroshima University) and Professor H. Tukada (Yokohama City University) for their technical assistance, continuing support and valuable discussions.

\section{References}

1) G. Ciamician and P. Silber, Ber. Dtsch. Chem. Ges., 33, 2911 (1900).

2) G. Ciamician and P. Silber, Ber. Dtsch. Chem. Ges., 34, 2040 (1901).

3) A. Schoenberg, "Preparative Organic Chemistry," Springer Verlag, Berlin (1968).

4) S. K. Chattopadhyay and B. B. Craig, J. Phys. Chem., 91, 323 (1987).

5) D. Gravel, J. Hebert, and D. Thoraval, Can. J. Chem., 61, 400 (1983).

6) W. N. R. Pilai, Synthesis, 1980, 1. 
7) M. Wilcox, R. W. Viola, K. W. Johnson, a. P. Billington, B. K. Carpenter, J. A. McCray, A. Guzikowski, and G. P. Hess, J. Org. Chem., 55, 1585 (1990).

8) J. F. Cameron and M. J. Frechet, J. Am. Chem. Soc., 113, 4303 (1991), and references cited therein.

9) J. A. McCray and D. R. Trentham, Ann. Rev. Biophys. Chem., 18, 239 (1989).

10) S. R. Adams and R. Y. Tsien, Ann. Rev. Physiol., 55, 755 (1993).

11) J. W. Walker, G. P. Reid, J. A. McCray, and D. R. Trentham, J. Am. Chem. Soc., 110, 7170 (1988)

12) E. Reichmanis, C. W. Wilkins, Jr., and E. A. Chandross, $J$. Vac. Sci. Technol., 19, 1338 (1981).

13) C. W. Wilkins, Jr., E. Reichmanis, and E. A. Chandross, $J$. Electrochem. Soc., 129, 2252 (1982).

14) E. Reichmanis, C. W. Wilkins, Jr., and E. A. Chandross, $J$. Electrochem. Soc., 130, 1433 (1983).

15) E. Reichmanis, R. Gordon, C. W. Wilkins, Jr., and H. Schonhorn, J. Polym. Sci., Chem. Ed., 21, 1075 (1983).

16) P. C. Scholl and M. R. van de Mark, J. Org. Chem., 38, 2376 (1973).

17) R. Kasai, K. Shinzo, O. Tanaka, and K.-I. Kawai, Chem. Pharm. Bull., 22, 1214 (1974).

18) R. Breslow, Chem. Soc. Rev., 1, 553 (1972).

19) R. Nakagaki, Y. Tanimoto, and K. Mutai, J. Phys. Org. Chem., 6, 381 (1993), and references cited therein.

20) E. Havinga, R. O. de Jongh, and W. Dorst, Recl. Trav. Chim. Pays-Bas, 75, 378 (1956).

21) J. Cornelisse and E. Havinga, Chem. Rev., 75, 353 (1975).

22) E. Havinga and J. Cornelisse, Pure Appl. Chem., 47, 1 (1976).

23) R. Nakagaki, Yuki Gosei Kagaku Kyokai Shi (J. Synth. Org. Chem. Jpn.), 40, 651 (1982).

24) K. Mutai and R. Nakagaki, Chem. Lett., 1984, 1537.

25) K. Mutai, R. Nakagaki, and H. Tukada, Bull. Chem. Soc. Jpn., 58, 2066 (1985).

26) K. Mutai and R. Nakagaki, Bull. Chem. Soc. Jpn., 58, 3663 (1985).

27) N. J. Bunce, S. R. Cater, J. C. Scaiano, and L. J. Johnston, J. Org. Chem., 52, 4214 (1987).

28) A. Cantos, J. Marquet, and M. Moreno-Manas, Tetrahedron Lett., 28, 4191 (1987).

29) A. Cantos, J. Marquet, M. Moreno-Manas, and A. Castello, Tetrahedron, 44, 2607 (1988).

30) G. G. Wubbels, E. J. Snyder, and E. B. Coughlin, J. Am. Chem. Soc., 110, 2543 (1988).

31) J. Malkin, "Photophysical and Photochemical Properties of Aromatic Compounds," CRC Press, Boca Raton (1992).

32) H. Shizuka, N. Maeno, and K. Matsui, Mol. Photochem., 4, 335 (1972).

33) K. Mutai, S. Kanno, and K. Kobayashi, Tetrahedron Lett., 1978, 1273 .

34) K. Mutai and K. Kobayashi, Bull. Chem. Soc. Jpn., 54, 462 (1981).

35) K. Mutai, K. Yokoyama, S. Kanno, and K. Kobayashi, Bull. Chem. Soc. Jpn., 55, 1112 (1982).

36) G. G. Wubbels, A. M. Halverson, and J. D. Oxman, J. Am. Chem. Soc., 102, 4849 (1980).

37) G. G. Wubbels and D. W. Celander, J. Am. Chem. Soc., 103, 7669 (1981).

38) H. A. Morrison, "The Chemistry of Nitro and Nitroso Groups," ed by H. Feuer, Wiley, New York (1969), Part 1, Chap. 4.
39) J. A. Barltrop and J. D. Coyle, "Excited States in Organic Chemistry," Wiley, New York (1975).

40) W. M. Horspool, "Aspects of Organic Photochemistry," Academic Press, London (1975).

41) N. J. Turro, "Modern Molecular Photochemistry," Benjamin/Cummings, Menlo Park (1978).

42) Y. L. Chow, "The Chemistry of Amino, Nitroso and Nitro Compounds and Their Derivatives," Wiley, New York (1982), Part 1, Supplement F, Chap. 6.

43) J. D. Coyle, "Introduction to Organic Photochemistry," Wiley, Chichester (1986).

44) E. Havinga and M. E. Kronenberg, Pure Appl. Chem., 16, 137 (1968)

45) J. Cornelisse, Pure Appl. Chem., 41, 433 (1975).

46) J. Cornelisse, G. P. de Gunst, and E. Havinga, Adv. Phys. Org. Chem., 11, 225 (1975).

47) J. Cornelisse, G. Lodder, and E. Havinga, Rev. Chem. Intermed., 2, 231 (1979).

48) a) A. N. Frolov, N. A. Kuznetsova, and A. V. El'tsov, Russ. Chem. Rev., 45, 1024 (1976); b) K. Akiyama, Y. Ikegami, T. Ikenoue, and S. Tero-Kubota, Bull. Chem. Soc. Jpn., 59, 3269 (1986).

49) D. Doepp, Top. Currr. Chem., 55, 49 (1975).

50) S. Nagakura, M. Kojima, and Y. Maruyama, J. Mol. Spectrosc., 13, 174 (1964).

51) H. H. Jaffe and M. Orchin, "Theory and Applications of Ultraviolet Spectroscopy," Wiley, New York (1962).

52) B. Vidal and J. N. Murrell, Chem. Phys. Lett., 31, 46 (1975).

53) R. Hurley and A. C. Testa, J. Am. Chem. Soc., 88, 4330 (1966).

54) T. P. Carsey, G. L. Findley, and S. P. McGlynn, J. Am. Chem. Soc., 101, 4502 (1979).

55) J. N. Murrell, "The Theory of the Electronic Spectra of Organic Molecules," Methuen, London (1963).

56) S. Nagakura and J. Tanaka, J. Chem. Phys., 22, 236 (1954).

57) S. Nagakura, J. Chem. Phys., 23, 1441 (1955).

58) J. Tanaka and S. Nagakura, J. Chem. Phys., 24, 1274 (1956).

59) R. Grinter and E. Heilbronner, Helv. Chim. Acta, 45, 2496 (1962).

60) H. Labhart and G. Wagniere, Helv. Chim. Acta, 46, 1314 (1963).

61) R. Nakagaki, I. Aoyama, K. Shimizu, and M. Akagi, J. Phys. Org. Chem., 6, 251 (1993).

62) O. S. Khalil, H. G. Bach, and S. P. McGlynn, J. Mol. Spectrosc., 35, 455 (1970).

63) W. Trotter and A. C. Testa, J. Am. Chem. Soc., 90, 7044 (1968).

64) J. C. Seliskar, O. S. Khalil, and S. P. McGlynn, "Excited States," ed by E. C. Lim, Academic Press, New York (1974), Vol. 1.

65) R. Li and E. C. Lim, J. Chem. Phys., 57, 605 (1972).

66) M. Akagi, Y. Amako, and H. Azumi, Nippon Kagaku Zasshi (J. Chem. Soc. Jpn.), 87, 689 (1966).

67) J. S. Brinen and B. Singh, J. Am. Chem. Soc., 93, 6623 (1971).

68) I. Fleming, "Frontier Orbitals and Organic Chemical Reactions," Wiley, New York (1976); N. D. Epiotis and S. Shaik, J. Am. Chem. Soc., 100, 29 (1978); N. D. Epiotis, "Theory of Organic Reactions," Springer, New York (1978).

69) K. Mutai, S. Kanno, and K. Kobayashi, Chem. Lett., 1978, 931.

70) K. Yokoyama, R. Nakagaki, J. Nakamura, K. Mutai, and S. 
Nagakura, Bull. Chem. Soc. Jpn., 53, 2472 (1980).

71) K. Yokoyama, J. Nakamura, K. Mutai, and S. Nagakura, Bull. Chem. Soc. Jpn., 55, 317 (1982).

72) K. Mutai, K. Kobayashi, and K. Yokoyama, Tetrahedron, 40, 1755 (1984).

73) J. P. Maier and D. W. Turner, J. Chem. Soc., Faraday Trans. 2, 69, 521 (1973).

74) H. Ogata, H. Onizuka, Y. Nihei, and H. Kamada, Bull. Chem. Soc. Jpn., 46, 3036 (1973).

75) A. van Vliet, J. Cornelisse, and E. Havinga, Tetrahedron, 26, 1061 (1971).

76) S. Nagakura and J. Tanaka, J. Chem. Phys., 22, 563 (1954); S. Nagakura and J. Tanaka, Bull. Chem. Soc. Jpn., 32, 734 (1959); S. Nagakura, Tetrahedron, 19, Suppl. 2, 361 (1963).

77) G. G. Wubbels, B. R. Svetson, and H. Saunders, J. Am. Chem. Soc., 111, 1018 (1989).

78) K. Mutai, unpublished work; see also: G. G. Wubbels and B. R. Svetson, J. Phys. Org. Chem., 2, 177 (1989).

79) R. Nakagaki, M. Hiramatsu, K. Mutai, and S. Nagakura, Chem. Phys. Lett., 121, 262 (1985).

80) K. Mutai, H. Tukada, and R. Nakagaki, J. Org. Chem., 56 4896 (1991).

81) K. Mutai, Tetrahedron Lett., 1971, 1125.

82) G. G. Wubbels, B. R. Svetson, and S. N. Kaganove, Tetrahedron Lett., 27, 3103 (1986); references cited in Ref. 80; see also reviews in: Chem. Rev., 92, No. 3 (1992).

83) K. Mutai, Y. Kajii, R. Nakagaki, and K. Obi, Tetrahedron Lett., in press.

84) K. Mutai, Bull. Chem. Soc. Jpn., 44, 2537 (1971).

85) R. Nakagaki, H. Sakuragi, and K. Mutai, J. Phys. Org. Chem., 2, 187 (1989).

86) R. Nakagaki, K. Mutai, and S. Nagakura, Chem. Phys. Lett., 154, 581 (1989).

87) M. Takami, T. Matsuura, and I. Saito, Tetrahedron Lett., 1974, 661; D. Doepp and J. Heufer, Tetrahedron Lett., 23, 1553 (1982).

88) V. Jagannadham and S. Steeken, J. Am. Chem. Soc., 106, 6542 (1984).

89) R. Hurley and A. C. Testa, J. Am. Chem. Soc., 90, 1949 (1968).

90) S. Hashimoto and K. Kano, Bull. Chem. Soc. Jpn., 45, 549 (1972).

91) G. G. Wubbels, J. W. Jordan, and N. S. Mills, J. Am. Chem. Soc., 95, 1281 (1973).

92) J. A. Barltrop and N. J. Bunce, J. Chem. Soc. C, 1968, 1468.

93) W. C. Petersen and R. L. Letsinger, Tetrahedron Lett., 1971,
2197.

94) G. Porter and P. Suppan, Trans. Faraday Soc., 61, 1664 (1965).

95) K. Itoh, H. Hayashi, and S. Nagakura, Mol. Phys., 17, 561 (1969).

96) A. R. Lepley and G. L. Closs, "Chemically Induced Magnetic Polarization," Wiley, New York (1973).

97) G. L. Closs, Adv. Magn. Reson., 7, 157 (1974).

98) L. T. Muus, P. W. Atkins, K. A. MacLauchlan, and J. B. Pedersen, "Chemically Induced Magnetic Polarization," Reidel, Dordrecht (1977).

99) "Spin Polarization and Magnetic Effects in Radical Reactions," ed by Yu. N. Molin, Elsevier, Amsterdam (1984).

100) N. J. Turro, Proc. Natl. Acad. Sci. U.S.A., 80, 609 (1983).

101) U. Steiner and T. Ulrich, Chem. Rev., 89, 51 (1989).

102) R. Nakagaki, M. Hiramatsu, K. Mutai, Y. Tanimoto, and S. Nagakura, Chem. Phys. Lett., 134, 171 (1987).

103) K. Mutai, R. Nakagaki, and H. Tukada, Chem. Lett., 1987, 2261.

104) R. Nakagaki, K. Mutai, M. Hiramatsu, H. Tukada, and S. Nagakura, Can. J. Chem., 66, 1989 (1988).

105) R. Nakagaki, K. Mutai, and S. Nagakura, Chem. Phys. Lett., 167, 439 (1990).

106) Y. Ishii, H. Tukada, R. Nakagaki, and K. Mutai, Chem. Lett., $1990,1559$.

107) K. Mutai, H. Tukada, and R. Nakagaki, Bull. Chem. Soc. Jpn., 66, 920 (1993).

108) B. Brocklehurst, Int. Rev. Phys. Chem., 4, 279 (1985).

109) H. Hayashi and S. Nagakura, Bull. Chem. Soc. Jpn., 57, $322(1984)$

110) M. Okazaki, Y. Tai, K. Nunome, K. Toriyama, and S. Nagakura, Chem. Phys., 161, 177 (1992).

111) Y. Fujiwara, M. Mukai, T. Tamura, Y. Tanimoto, and M. Okazaki, Chem. Phys. Lett., 213, 89 (1993).

112) Y. Nakamura, M. Igarashi, Y. Sakaguchi, and H. Hayashi, Chem. Phys. Lett., 217, 387 (1994).

113) R. Nakagaki, O. Takahira, and K. Hiruta, Chem. Phys. Lett., 233, 41 (1995).

114) R. Nakagaki, Y. Tsujimoto, and K. Mutai, Chem. Phys. Lett., 244, 388 (1995).

115) M. Hiramatsu, R. Nakagaki, Y. Tanimoto, K. Mutai, H. Tukada, and S. Nagakura, Chem. Phys. Lett., 142, 413 (1987).

116) F. J. J. de Kanter, J. A. den Hollander, A. H. Huizer, and R. Kaptein, Mol. Phys., 34, 857 (1977).

117) "CRC Handbook of Organic Photochemistry," ed by J. C. Scaiano, CRC Press, Boca Raton (1989). 

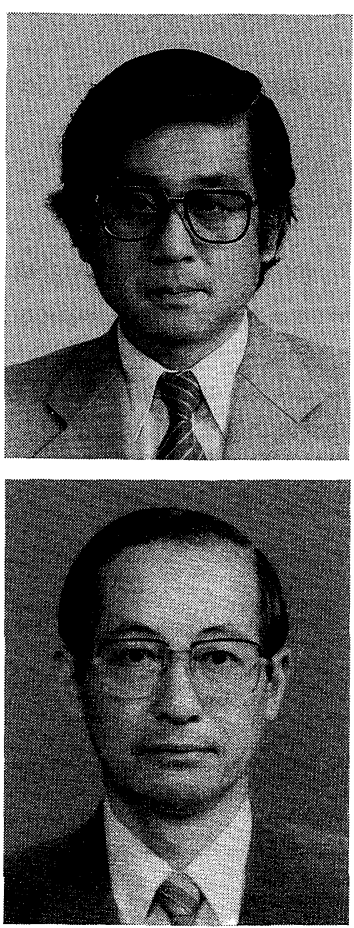

Ryoichi Nakagaki was born in Tokyo in 1950 and received a B. S. degree from Nagoya University in 1973. His graduate work was done at the University of Tokyo under the supervision of Professor Saburo Nagakura, and he obtained his Ph. D. in 1978. He has been continuing experimental research on photochemistry and magnetic field and magnetic isotope effects on chemical reactions since 1982 when he became a research associate at the Institute for Molecular Science. From 1993 - 1995 he was an adjunct associate professor of this Institute. He is now an associate professor in the Faculty of Pharmaceutical Sciences, Kanazawa University. His research interests are in switching of reaction pathways caused by small perturbations such as an external magnetic field.

Kiyoshi Mutai was born in Nagano in 1935. He was graduated from the University of Tokyo, getting a B. Sc. degree in 1958. His graduate work was done under the direction of Prof. Michinori Ōki at the same university, where he received an M. S. degree in 1960, followed by a Ph. D. in 1963. He continued his work as a research associate and moved to College of Arts and Sciences, the University of Tokyo in 1967 as an associate professor. From 1980-1982 he was an adjunct associate professor of Institute for Molecular Science. He is now a professor of chemistry at Graduate School of Arts and Sciences. His present research interests are mainly directed to molecular interactions and mechanistic aspects of photochemical reactions in the field of Organic Chemistry. 